\title{
ĐÁNH GIÁ Độ XƠ HÓA GAN BẰNG KỸ THUÂT REAL TIME ELASTOGRAPHY Ở BÊ̂NH NHÂN VIÊM GAN VIRUS B MẠN TÍNH
}

\author{
Nguyễn Công Long', Nguyễn Thị Thu Trang ${ }^{2}$, Vũ Trường Khanh ${ }^{1}$
}

\section{TÓM TẮT}

Mục tiêu: Đánh giá mức độ xơ hóa của gan bằng phương pháp đo độ đàn hổi gan (LFI) ở bệnh nhân viêm gan virus $B$ mạn tính và xác định tính chính xác của chỉ số LFI so với mô bệnh học và fibroscan. Đối tượng và phương pháp: Tổng số 32 bệnh nhân chẩn đoán viêm gan virus $B$ mạn tính được sinh thiết gan để phân loại mức độ xơ theo Metavir, tất cả các bệnh nhân được đo độ đàn hồi của gan và tính chỉ số LF́ và tính chỉ số fibroscan, và so sánh giá trị đánh giá mức độ xơ của phương pháp đo mức độ đàn hồi gan với kết quả mô bệnh học và fibroscan. Kết quả: 32 bệnh nhân viêm gan virus $B$ mạn tính được chẩn đoán bắng sinh thiết gan và đánh giá mức độ xơ dựa trên bảng điểm Metavir. Kết quả cho thấy trung bình chỉ số LFI khác nhau ở các giai đoan xơ từ $1,45 \pm 0,35$ với F0 tới 3,59 $\pm 0,51$ với $F 4$ và có sự tương quan trực tiếp $(r=0,9119)$ giữa chỉ số LFI và chỉ số Metavir $(p<0,001)$. Cả phương pháp đo độ đàn hổi gan và fibroscan đều có giá tri dư báo chỉ số xơ. Kết luân: Nghiên cứu cho thấy rằng chỉ số LFI có liên quan chặt với chỉ số mô bệnh học và fibroscan, phương pháp đơ độ đàn hồi gan trên siêu âm có thể sử dụng như một phương pháp dự báo mức độ xơ ở gan.

Tư khóa: Độ đàn hồi gan, xơ gan

\section{SUMMARY}

\section{EVALUATE HEPATIC FIBROSIS IN} PATIENTS WITH CHRONIC HEPATITIS B WITH REAL-TIME TISSUE ELASTOGRAPHY

Objective: To determine the formula of the liver fibrosis index (LFI) for chronic hepatitis $\mathrm{B}(\mathrm{CHB})$ by real time tissue elastography and to validate the diagnostic accuracy of LFI the for hepatic fibrosis compared with liver biopsy and fibroscan. Subjects and methods: Thirty-two prospectively enrolled patients with chronic hepatitis $\mathrm{B}(\mathrm{CHB})$ underwent assess liver fibrosis index as well as perform fibroscan. The fibrosis stage according to Metavir score was diagnosed from pathological specimens obtained by ultrasound-guided liver biopsy. LFI score were compared with the pathological fibrosis stage diagnosis Metavir score and Fibroscan score, and the diagnostic performances of the indexes were compared. Results: Of 32 patients CHB were diagnosed by liver biopsy and quantified degree of fibrosis using Metavir score. Results showed the mean LFI score for different stages of fibrosis ranged from

\footnotetext{
1 Trung tâm tiêu hóa bệnh viện Bạch mai ¿Bênh viên đa khoa tỉnh Nghê an

Chịu trách nhiệm chính: Nguyễn Công Long

Email: nguyenconglongbvbm@gmail.com

Ngày nhận bài: 3.6.2021

Ngày phản biên khoa học: 30.7.2021

Ngày duyệt bài: 6.8.2021
}

$1,45 \pm 0,35$ for $\mathrm{F} 0$ to $3,59 \pm 0,51$ for $\mathrm{F} 4$ and a direct correlation ( $r=0,9119)$, was found to exist between LFI score and Metavir score $(p<0,001)$. All LFI score and fibroscan have a value predicting liver fibrosis. Conclusion: we found that our newly developed LFI score is strongly correlated with histological fibrosis and fibroscan score, and real time elastography can be use as a method to predicting liver fibrosis

Key words: LFI; liver fibrosis

\section{I. ĐĂT VẤN ĐỀ}

Viêm gan mạn tính là bệnh lý thường gặp gây nhiêu hậu quả nghiêm trọng như xơ gan, ung thư gan. Viêm gan mạn có nhiều nguyên nhân như viêm gan virus $B, C$, rượu, do thuốc, viễm gan tự miển... Việt Nam là nước có tỉ lệ nhiếm viêm gan virus $B$ cao, trên $10 \%$, tỉ lệ nhiểm virus viêm gan $C 1-3 \%$ tùy thuộc vào vùng dịch tễ, tình trạng lạm dụng rượu cũng đang ngày càng gia tăng dẫn đến số lượng bệnh nhân viêm gan mạn ngày càng nhiêu [1].

Việc xác định chính xác giai đoạn xơ hoá gan rất quan trọng trong tiên lượng, tâm soát, và quyết định điều trị ở bệnh nhân có bệnh gan mạn trong thực hành lẩm sàng. Cho đến nay, sinh thiết gan vẫn được xem là tiêu chuẩn vàng để đánh giá mức độ xớ hoá gan [2]. Vì vậy, hiện nay trên thế giới đang phát triển nhiêu phương pháp đánh giá tình trạng xơ hoá gan không xâm nhập như các chỉ số sinh hoá (Fibrotest, APRI, FIB4, Fibrometre kỹ thuật Real time Elastography- một kỹ thuật mới, có tích hợp với đâuu dò $B$ Mode, Real time Elastography có thể thực hiện được ở bệnh nhân có cổ trướng, khoang liên sườn hẹp, làm tăng độ chính xác hơn cho kỹ thuật Elastography trong đánh giá độ xơ hoá của gan. Chính vì thế chúng tôi tiến hành nghiên cứu đề tài với mục đích đánh giá sự thay đổi chỉ số Real time Elastography ở bệnh nhân viêm gan mạn và và tìm hiểu giá trị của Real time Elastography trong đánh giá xơ hoá gan ở bệnh nhân viêm gan mạn.

\section{II. ĐỐI TƯỢNG VÀ PHƯƠNG PHÁP NGHIÊN CỨU}

Đối tượng: Nghiên cứu 32 bệnh nhân khám ngoại trú tại phòng khám tiêu hoá bệnh viện Bạch Mai được chẩn đoán xác định là viêm gan virus $B$ mạn tính dựa vào khám lâm sàng, cận lâm sàng kết quả mô bệnh học, tiêu chuẩn loại trừ các bệnh nhân không đồng ý tham gia nghiên cứu. 
Phương pháp: Bệnh nhân chẩn đoán viêm gan man tính được tiến hành sinh thiết gan và tính điểm xơ hóa theo Metavir, làm fibroscan, và được tiến hành đo độ đàn hồi gan bằng máy siêu âm Aloka của hãng Hitachi, Nhật Bản, có tích hợp Real time Elastography. Sau đó tính độ nhạy và độ đặc hiệu của từng phương pháp fibroscan, và độ đàn hồi sinh thiết gan so với chuẩn là kết quả sinh thiết gan.

Xử lý số liệu : Sau khi thu thập đầy đủ các số liệu, quá trình xử lý được làm trên máy tính với phần mềm xử lý số liệu SPSS 16.0, tính hê sô tương quan $r$, giá trị $P<0,05$ được xác định là mức khác biệt có ý nghĩa thống kê.

\section{KẾT QUẢ NGHIÊN CỨU}

Bảng 1. Đặc điểm cận lâm sàng nhóm bệnh nhân nghiên cứu

\begin{tabular}{|c|c|c|c|c|c|c|c|}
\hline \multicolumn{7}{|c|}{ Đặc điếm lâm sàng và cận lâm sàng } \\
\hline $\begin{array}{c}\text { Đặc điếm } \\
\text { nhómm } \\
\text { phân tích }\end{array}$ & Tuổi & $\begin{array}{c}\text { Giới } \\
\text { (Nam/nư) }\end{array}$ & $\begin{array}{c}\text { Đau hă sườn phải } \\
\text { sàng da }\end{array}$ & AST & ALT & $\begin{array}{c}\text { Bilirubin } \\
\text { toàn phân }\end{array}$ \\
$\begin{array}{c}\text { Tống số } \\
\text { bênh nhân } \\
\text { (n = 32) }\end{array}$ & $\begin{array}{c}40,9 \pm 11,5 \\
(23-67)\end{array}$ & $\begin{array}{c}21 / 11 \\
(65,6 / 34,8 \%)\end{array}$ & $\begin{array}{c}5 \\
(16,7 \%)\end{array}$ & $\begin{array}{c}2 \\
(6,5 \%)\end{array}$ & $\begin{array}{c}56,4 \pm 56,5 \\
(20-343)\end{array}$ & $\begin{array}{c}77,9 \pm 103,4 \\
(19,4-597)\end{array}$ & $\begin{array}{c}13,2 \pm 4,7 \\
(7,2-26,2)\end{array}$ \\
\hline
\end{tabular}

Bảng 2. Chỉ số LFI với mức độ xớ hóa theo Metavir

\begin{tabular}{|c|c|c|c|c|}
\hline \multirow{2}{*}{ Metavir } & \multicolumn{3}{|c|}{ LFI } & \multirow{2}{*}{ p } \\
\cline { 2 - 4 } & n & Trung bình & SD & \multicolumn{1}{|c|}{} \\
\hline F0 & 10 & 1,45 & 0,35 & \multirow{3}{*}{0,0001} \\
\hline F1 & 7 & 2,03 & 0,26 & \\
\hline F2 & 0 & - & - & \multirow{2}{*}{0,27} \\
\hline F3 & 8 & 2,74 & 0,27 \\
\hline F4 & 7 & 3,59 & 0,51 \\
\hline Chung & 32 & 2,37 & 0,89 & \\
\hline
\end{tabular}

Kết quả bảng trên cho thây, chỉ số LFI trung bình của nhóm bệnh nhân nghiên cứu là $2,37 \pm 0,89$. Chỉ số LFI tăng dần theo các mức độ xơ hóa theo Metavir, thấp nhất ở nhóm không xơ hóa (F0) là $1,45 \pm 0,35$ và cao nhất ở nhóm xơ gan (F4) là $3,59 \pm 0,51$.

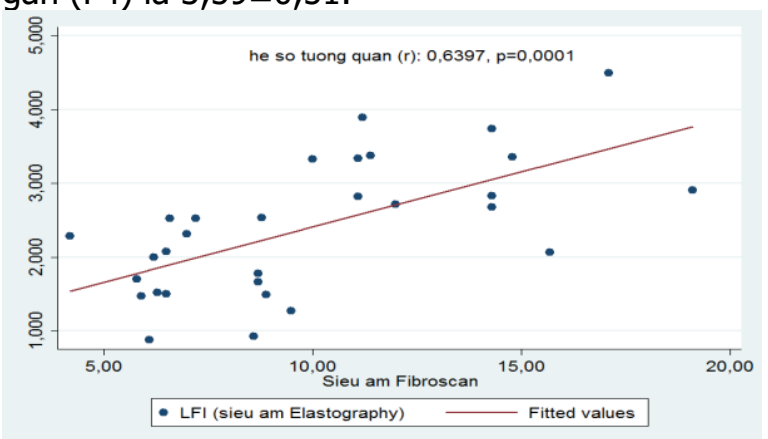

Biểu đồ 1. Môi tương quan giữa chỉ số LFI và chí số Fibroscan

Bảng 3. Chỉ số FibroScan với mức độ xơ hóa theo phân loại Metavir

\begin{tabular}{|c|c|c|c|c|}
\hline \multirow{2}{*}{ Metavir } & \multicolumn{2}{|c|}{ FibroScan (KPa) } & \multirow{2}{*}{ p } \\
\cline { 2 - 4 } & $\mathbf{n}$ & TB & SD & \multirow{3}{*}{} \\
\hline F0 & 10 & 7,25 & 1,47 & \multirow{2}{*}{0,0012} \\
\hline F1 & 6 & 7,98 & 4,06 & \multirow{2}{*}{$<0,05$} \\
\hline F2 & 0 & - & - & \\
\hline F3 & 8 & 10,54 & 2,95 & \\
\hline
\end{tabular}

\begin{tabular}{|c|c|c|c|}
\hline F4 & 7 & 14,14 & 3,14 \\
\hline Chung & 31 & 9,80 & 3,84 \\
\hline
\end{tabular}

Chỉ số FibroScan trung bình của nhóm bệnh nhân nghiên cứu là $9,8 \pm 3,8$. Chỉ số FibroScan tăng dần theo các mức độ xơ hóa theo Metavir một cách có ý nghĩa thổng kê (với $p<0,001$, Kruskal-Wallis test).

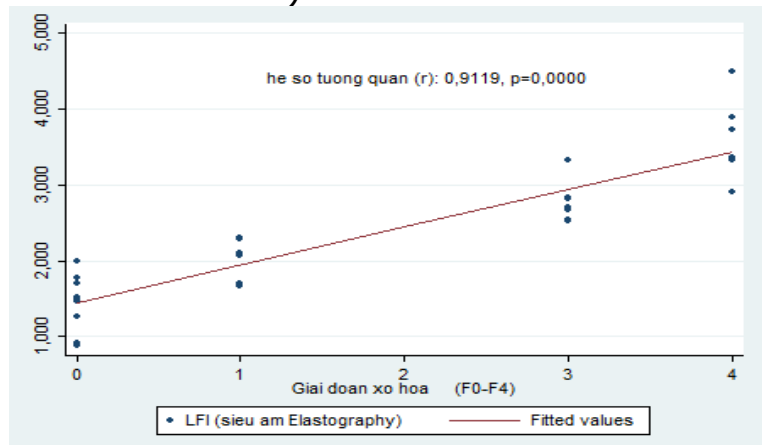

Biểu đồ 2. Môii tương quan giữa chỉ số LFI và mức độ xơ hóa gan theo Metavir

\section{BÀN LUẬN}

Trong nghiên cứu của chúng tôi 32 bênh nhân viêm gan virus $B$ mạn tính được sinh thiết gan và đọc mô bệnh học theo tiêu chuẩn Metavir để chia mức độ xơ hóa, và các bệnh nhân đều được đánh giá mức độ xơ hóa gan theo phân loạn fibroscan, và đo LFI

Kết quả cho thấy Chỉ số LFI và mức độ xơ hóa gan theo Metavir có mối tương quan đồng biến chặt chẽ $(r=0,9119>0, p<0,001)$. Chỉ số LFI tăng dần theo các mức độ xơ hóa gan khác nhau ở các giai đoạn xơ từ $1,45 \pm 0,35$ với $F 0$ tới $3,59 \pm 0,51$ với $F 4$. Kết quả này tương đồng nghiên cứu của Fankun Meng và cộng sự trên 289 bệnh nhân viêm gan $B$ mạn, với $r=0.667$, $\mathrm{p}<0.001[3]$. Tương tự kết quả nghiên cứu của 
Kenij Fujimoto và cộng sự ở 310 bệnh nhân viêm gan C mạn, nghiên cứu cũng cho thấy có mối tương quan đồng biến cao giữa chỉ số LFI với các giai đoạn xơ hóa gan với $r=0.68$ [4].

Kỹ thuật RTE là kỹ thuật mới, trên thế giới chưa có nhiều nghiên cứu như đối với kỹ thuật Fibroscan, và trong nước hiện tại chưa có nghiển cứu nào về kỹ thuật này. Chính vì vậy, nghiên cứu của chúng tôi đóng góp những nhận xét ban đầu về giá trị của RTE đối với việc đánh giá dộ xơ hóa gan, có đối chiếu với bảng phân loại Metavir trên mô bênh hoc.

ở nghiên cứu của chúng tôi, không có bệnh nhân nào xơ hóa gan ở giai đoạn F2, do vậy chúng tôi không xác định được điểm cut off của LFI đối với giai đoạn này. Đây cũng là một hạn chế của đề tài, do thời gian nghiên cứu ngắn, số lượng bệnh nhân nghiên cứu ít, để có thể đưa ra được kết quả đầy đủ, rõ ràng hơn chúng tôi cần mở rộng đề tài, phát triển thêm số lượng bệnh nhân nhiều hơn. Giá trị ngưỡng của LFI đối với giai đoạn $\mathrm{F} \geq 3$ là 2.41 với diện tích dưới đường cong là 0.714 , độ nhạy $100 \%$ độ đặc hiệu 70.8\%. Giá trị ngưỡng của LFI đối với giai đoạn F4 là 2.87, diện tích dưới đường cong là 0.994, độ nhạy $100 \%$, độ đặc hiệu $96 \%$. Kết quả nghiên cứu của chúng tổi tương đồng với nghiên cứu của Fujimoto, Ferrailoli $[5,6]$, chỉ số LFI và chỉ số Fibroscan có mối tương quan đồng biến khá chặt chẽ $(r=0,6397>0, p<0,001)$. Trong nghiên cứu của chúng tôi, chỉ số LFI và chỉ số Fibroscan đều có giá trị trong chẩn đoán xơ gan với AUROC tương ứng là 0.994 và 0.908 . Tuy nhiên, Fibroscan có một số hạn chế như không chính xác ở bênh nhân béo phì, bênh nhân cổ trướng, hay các bệnh nhân có khoang liên sườn hẹp, trong khi RTE có thể khắc phục được những nhược điểm này, do vậy RTE hứa hẹn là một kỹ thuật mới để đánh giá độ xơ hóa gan trong tương lai, có thể thay thế cho Fibroscan.

\section{KẾT LUÂ̂N}

Fibroscan là kỹ thuật Elastography được ứng dụng và nghiên cứu nhiều trên thế giới, đã được chứng minh giá trị trong chẩn đoán mức độ xơ hóa gan ở bệnh nhân viêm gan mạn. Trong nghiên cứu của chúng tôi, cho thấy, cả kỹ thuật RTE và kỹ thuật Fibrscan đều có giá trị cao trong chẩn đoán mức độ xớ hóa gan

\section{TÀl LIỆU THAM KHẢO}

1. Nguyễn Công Long và cs, đánh giá đáp ứng điêu trị viêm gan virus $B$ mạn tính có $\mathrm{HBeAg}(+)$ và HBeAg(-) bằng entecavir. Đ̇ại học Y Hà Nội, 2012. luận an tiến sỹ y học.

2. Thảng, H.T., Sinh thiết gan; Bệnh tiêu hóa - gan mật. 2002: Nhà xuất bản Y học.

3. MD Fankun Meng, M.Y.Z., MD Qi Zhang và et al, Noninvasive Evaluation of Liver Fibrosis Using Real-time Tissue Elastography and Transient Elastography (FibroScan). J Ultrasound Med, 2015. 34: p. 403-410 |0278-4297 |www.aium.org.

4. Kenji Fujimoto, M.K., Akiko Tonomura et al, Non- invasive evaluation method of the Liver fibrosis using Real time tissue Elastography Usefulness of Judgment liver fibrosis stage by liver fibrosis index (LF index). Kanzo, 2010: p. 51:539- 541.

5. Fujimoto, K.M., Kudo $M$ et al, Novel Image analysis method using ultrasound elastography for noninvasive evaluation of hepatic fibrosis in patient with chronic hepatitis C. Oncology, 2013. 84 Suppl 1: p. 3- 12.

6. Ferraioli G, T.C., Malfitano A et al, Performance of Real time strain elastography, transient elastography, and aspartate to platelet ratio index in the assessment of liver fibrosis in chronic hepatitis C. AJR Am J Roentgenol, 2012. 199: p. $19-25$.

\section{ĐẶC ĐIỂM LÂM SÀNG VÀ CHẤT LƯợNG CUộC SỐNG CỦA BÊ̂NH NHÂN PARKINSON THỂ CỨNG}

\section{TÓM TẮT}

Mục tiêu: Mô tả đặc điểm lâm sàng và chất lượng

\footnotetext{
${ }^{1}$ Bênh viên $E$

${ }^{2}$ Trường Đại học Y Hà Nội

${ }^{3}$ Bệnh viện Lão khoa Trung Uơng

Chịu trách nhiệm chính: Đào Thùy Dương

Email: duongbin.92@gmail.com

Ngày nhận bài: 2.6.2021

Ngày phản biện khoa học: 27.7.2021

Ngày duyệt bài: 6.8.2021
}

\section{Đào Thùy Dương1, Nguyễn Thanh Bình ${ }^{2,3}$}

cuộc sống (Quality of Life - QoL) của bệnh nhân Parkinson thể cứng. Đối tượng và phương pháp nghiên cứu: Nghiên cứu mồ tả cắt ngang trên 60 bệnh nhân Parkinson thể cứng tại Bệnh viện Lão khoa Trung Ương từ tháng 08 năm 2020 đến tháng 06 năm 2021, chẩn đoán bệnh Parkinson theo tiêu chuẩn của Ngân hàng não hội Parkinson Vương quốc Anh (UKPDSBB/United Kingdom Parkinson's Disease Society Brain Bank), tiêu chuẩn thể cứng theo Thang điểm đánh giá bệnh nhân Parkinson (UPDRS), chất lương cuốc sống bềnh nhân theo Thang điểm đánh giá chất lượng cuộc sống bệnh nhân Parkinson PDQ-39 (Parkinson's Disease Questionnaire). Kết quả:Tuổi 